\title{
A Methodology of Employing Spreadsheet Software as a Tool for Integrating Web Services
}

\author{
Somchai Chatvichienchai and Wataru Miyagi
}

\begin{abstract}
Web services are client and server applications that communicate over hypertext transfer protocol (HTTP) of the world wide web's (WWW).Web services are built around the Web browser standards and can be used by any browser on any platform. However, web browsers themselves lack the ability to analyst and process web data offline as users need. In order to perform data analysis, users have to output data from web sites in CSV or XML format, and have spreadsheet software (such as Microsoft Excel, etc.) imported the data. This inconvenient and time-consuming task is a bottle neck in analyzing data of web applications. The objective of this paperis to present a methodology that employs Excel as a toolfor web serviceintegration and offline data processing. Furthermore, this paper presents the technical feature comparison between webbrowsers and Excel in aspect of web application client. Based on this methodology, we have developed an Excel-based online accommodation search program thatintegrates web services of Google Map and Rakuten Travel which is the biggest accommodation booking web site of Japan.
\end{abstract}

Index Terms-Spreadsheet software, XML, web service, Google Map, search.

\section{INTRODUCTION}

Web services are client and server applications that communicate over hypertext transfer protocol (HTTP) of the world wide web's (WWW). Web services are popular due to the ubiquity of web browsers, and the convenience of using a web browser as a client, sometimes called a thin client. The ability to update and maintain web applications without distributing and installing software on potentially thousands of client computers is a key reason for their popularity, as is the inherent support for cross-platform compatibility. Web applications commonly use a combination of server-side script (such as ASP, PHP, etc.) and client-side script (HTML, JavaScript, etc.) to develop the application. The client-side script deals with the presentation of the information while the server-side script deals with all the hard stuff like storing and retrieving the information. Recently governments and public administrations started to publish large amounts of structured data on the web, mostly in the form of tabular data [1]. However, thin clients themselves lack the ability to analyst and process web data offline as users need. In order to perform data analysis, users have to copy the data from the web pages and paste it to worksheet cell. This inconvenient and time-consuming task is a bottle neck in analyzing data of web applications.

Manuscript received March 10, 2014; revised June 12, 2014.

The authors are with the Dapartment of Information and Media Studies of University of Nagasaki, Japan (e-mail: somchaic@sun.ac.jp, B2210060@sun.ac.jp).
Some work has been contributed to solve this problem. SPREANS [2] is a spreadsheet that edits XML data and includes browser functionality for web service access. The use of SPREANS as a browser replaces the main uses of client-side scripting (such as calculation and constraint checking) by declarative specifications. PadSpace [3] is a framework for the service federation of web resources. It provides users an end-user supporting tool for composing web applications, web services and local functional resources without writing any program code.However, the main drawback of these tools is that theylack programming feature that automates sequential and continuous processing of data from web services. This drawback severely limits the scope of web applications of the tools.

Excel [4] is powerful spreadsheet software that isused to manipulate, analyze, and present data. Excel has Visual Basic for Applications (VBA) [5], a programming language that gives users the ability to perform a mundane, repetitive taskautomatically, or to perform some task that the user interface does not seem to address. Furthermore, Excel provides necessary libraries that can be used by developers to connect Excel with external data such as webs, databases, text files, etc. Therefore, Excel is a feasible tool for integrating data of web services.

The objective of this paper is to present a methodology that employs Excel as a toolfor developing programs that integrateweb services' data and process the data offline. Furthermore, technical feature comparison between webbrowsers and Excel clientin an aspect of web application clientis presented. Based on thismethodology, we have developed an Excel-based online accommodation search program by integrating web services of Google Map and Rakuten Travel which is the biggest accommodation booking web site of Japan.

\section{EMPloying ExCEL AS A Web APPliCAtion Client}

The benefits of employing Excel as a webapplication client are summarized as follows.

1) Excel can be connected to external data such as a web page, a database, an XML [6] file, a text file, or in one of many other places. By employing external data source connectivity and VBA, Excel can become a thick webapplication client. Excel contains powerful XML-based functionality [7], including web service data exchange. For example, using the above features of Excel, developers can create a variety of solutions that help users increase their productivity on Yahoo! Japan. Web services offered by Yahoo! Japan allow users to use Excel to manage dynamic listing data, such as pricing and bids, and update this data automatically as 
changes occur.

2) VBA can be used to develop event-driven applications where a user action or system event runs an event procedure. Thus, the order in which VBA code is run depends on the order in which events occur; the order in which events occur is determined by the user's actions. This is the essence of graphical user interfaces and event-driven programming: The user is in charge, and VBA code responds accordingly. In a traditional procedural program (such as C, Java, etc.), the application rather than an event controls the portions of code that are run. It begins with the first line of code and follows a defined pathway through the application, calling procedures as needed.

3) Developing complex logic in Excel is much more efficient than hand coding in a software language such as C, Java, etc. By using built-in or intrinsic functions of Excel, developers can create calculations and data transformation routines in an Excel worksheet (sheet, for shot) in a fraction of the time that it takes to do the same in code of other software language. Beginning developers can be effective at coding logic that might otherwise require a very skilled resource.

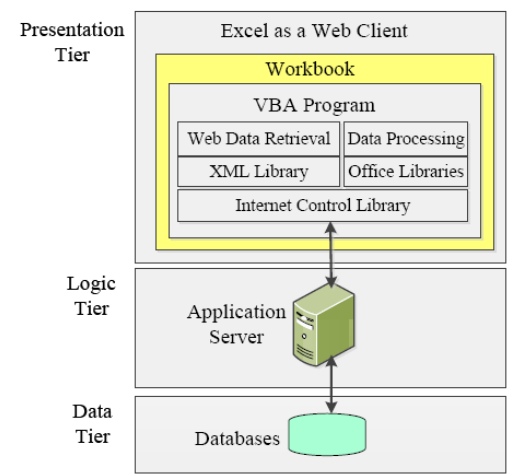

Fig. 1. Three tiers ofa webapplication that employs Excel as a web client.

To understand the web application architecture that makes web service systems extensibility, methodology of developing and integratingweb applications is presented. Web services standards [8] are closely linked to the conventional way of structuring web applications as 3-tier architectures [9]. The design goal of 3-tier architectures (see Fig. 1) is to separate an application's logic into three separate tiers: a database system that stores persistent data as the lowest tier; an application server that contains most of the application logic as the middle-tier; and the client that contains some client-specific application logic and presentation as the top tier.

Consider the main component of Excel connecting to application servers shown in Fig. 1. In order to allow VBA program to access web services, developers have to include Microsoft internet control library and Microsoft XML library into VBA program. They also have to include necessary office libraries into VBA program in order to process retrieved web data and store it to client side's data source. Excel VBA sends HTTP request with parameters specifying of web service API and its data for executing web service. Note that web service APIs are provides by web sites. The output of the HTTP request is send back to the VBA program in HTML or XML format. Users can process the output data by manual operation or VBA program.

TABLE I: TECHNICAL FEATURE COMPARISON BETWEEN WEB BROWSERS AND EXCEL-BASED CLIENTS

\begin{tabular}{|l|l|l|}
\hline \multicolumn{1}{|c|}{ Technical features } & \multicolumn{1}{|c|}{ Web browsers } & \multicolumn{1}{|c|}{ Excel-based clients } \\
\hline 1. User experience & Application-centric & Data entry / Analysis reporting tool \\
\hline $\begin{array}{l}\text { 2. Development } \\
\text { environment }\end{array}$ & $\begin{array}{l}\text { Programming by using script } \\
\text { languages (s.a. PHP, JavaScript, etc.), } \\
\text { presentation definition language (s.a. } \\
\text { CSS, etc.) and application program } \\
\text { interfaces (s.a. DOM, etc.) }\end{array}$ & $\begin{array}{l}\text { Programming by using Excel VBA macro } \\
\text { or Visual Studio Tools for Office [10] }\end{array}$ \\
\hline $\begin{array}{l}\text { 3. Runtime } \\
\text { environment }\end{array}$ & $\begin{array}{l}\text { The operating systems which can run } \\
\text { Web browsers and the scripts } \\
\text { embedded in the Web pages. }\end{array}$ & $\begin{array}{l}\text { Limited to the operating systems that can } \\
\text { run Excel. }\end{array}$ \\
\hline 4. Content control & $\begin{array}{l}\text { Allows customized or fine-grained } \\
\text { control over page elements }\end{array}$ & $\begin{array}{l}\text { Allows customized or fine-grained control } \\
\text { over cells of worksheet }\end{array}$ \\
\hline $\begin{array}{l}\text { 5. Validation of data } \\
\text { when user enters } \\
\text { values. }\end{array}$ & $\begin{array}{l}\text { Need to develop the scripts to validate } \\
\text { the data fields. }\end{array}$ & $\begin{array}{l}\text { During template design, validation can be } \\
\text { added to data fields (cells) with minimal } \\
\text { code. At runtime the fields are validated } \\
\text { offline. }\end{array}$ \\
\hline $\begin{array}{l}\text { 6. Web Page Flow } \\
\text { and Navigation }\end{array}$ & $\begin{array}{l}\text { Need to develop the scripts to handle } \\
\text { Web page navigation }\end{array}$ & $\begin{array}{l}\text { No need to handle Web page navigation. } \\
\text { Use VBA macro for controlling cursor } \\
\text { position on cells of the worksheets. }\end{array}$ \\
\hline 7. XML Integration & $\begin{array}{l}\text { Need to develop the scripts to map } \\
\text { XML schema to Web page fields. }\end{array}$ & $\begin{array}{l}\text { Native support for binding XML schema } \\
\text { to cells of the worksheets. }\end{array}$ \\
\hline 8. Reusability & Can be used in a Web client only & $\begin{array}{l}\text { The Excel template can be used in an } \\
\text { offline scenario or embedded within e-mail }\end{array}$ \\
\hline $\begin{array}{l}\text { 9. Integration with } \\
\text { the application } \\
\text { servers }\end{array}$ & $\begin{array}{l}\text { Need to develop program at Web } \\
\text { server side that allows data exchange } \\
\text { with the application server. }\end{array}$ & $\begin{array}{l}\text { Need to develop custom code that allows } \\
\text { data exchange between Excel and the } \\
\text { application server through standard Web } \\
\text { service. }\end{array}$ \\
\hline
\end{tabular}

Technical feature comparison between traditional webbrowsers and Excel in aspect of webapplication client is shown in Table I. For web applications which users need to input large amount of data to servers, using Excel-based clients can increase productivity better than using traditional HTML forms because users can validate the data save the data file offline. Since client computers only communicate with the application servers when users send the data from Excel to the server, overhead cost of network communication is much lesser than that of webbrowsers.

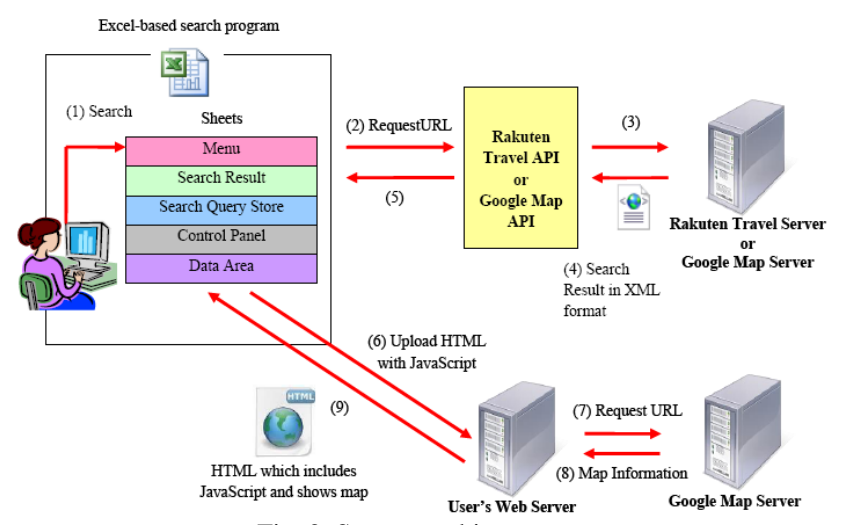

Fig. 2. System architecture.

\section{EXCEL AS A TOOL FOR INTEGRATING SEARCH FunCTIONS OF ACCOMMODATION BOOKING WEB SITE AND GOOGLE MAP}

\section{A. Background and Problem Definition}

Online accommodation reservation is a popular method for booking hotel rooms. Travelers can book rooms on a computer by using online security to protect their privacy and financial information and by using several online travel agents to compare prices and facilities at different hotels. Currently, Rakuten Travel is the biggest accommodation booking web site of Japan. Rakuten Travel allows users to search and book accommodations via web browser.

As result of investigation, wefound that Rakuten Travel 
web site lacks accommodation search by destination. This search function allows users finding out accommodations nearby the place of destination (such as the place where users want to go for sightseeing, etc.). Currently, users have to define search conditions such as check-in and check-out dates, etc. Next they have to define the location of accommodations by clicking prefecture link and city link, respectively. The search system will output a list and information of the accommodations which are inside the selected city and meet the search condition defined by users. Users can use map function of Rakuten Travel to show the locations of accommodations. However, the map function cannot show the distance from the accommodations to the place of destination. If they want to investigate the distance, they have to use navigation function of Google Map. Users have to repeat this time-consuming investigation operation until they find the accommodation which meets their need.

\section{B. Solution}

Our goal is to develop "accommodation search system" that allows users to search Rakuten Travel's accommodations by the place of destination. In order to achieve the goal under low development cost, we decide to develop the program by using Excel as a webapplication client. We use Rakuten Travel APIs [11] to access accommodation database of Rakuten Travel. We use Google Map via Google Maps JavaScript API [12] to display the accommodations which are near the place of destination on the map. Here, a user denotes one who uses this search system to find Rakuten Travel's accommodations. The system provides the following three new search methods.

- Accommodation search by the place of destination. Users enter place name (such as Tokyo Sky Tree, Asakusa Shrine, Osaka Castle, etc.) and the upper limit distance in kilometer from the place of destination to accommodations as search condition.

- Accommodation search by prefectures (such as Tokyo-to, Hokkai-do, Osaka-fu, Kyoto-fu and remaining prefectures).

The program will search the accommodations which are in the specified prefecture and also match with refined

\section{search condition.}

- Accommodation search by keywords that appear in the accommodations' homepage of Rakuten Travel.

For example, users enter "globefish" as a keyword to search the accommodations that provide globefish dish.

\section{System Drchitecture of the Proposed Search System}

The architecture of the system is shown in Fig. 2. Excel-based search program calls application program interfaces (APIs) of Rakuten Travel and Google Map to communicate Rakuten Travel server and Google Map server, respectively. The servers send data (such as search results, etc.) in XML format. The process outline of the system is explained as follow.

1) The user enters a search query at Excel sheet of the program.

2) Excel VBA generates a URL request based on user's search query.

3) The program connects to the servers by the URL request of (2).

4) The servers return accommodation information that is satisfied by user's search query. Note that the accommodation information is represented in XML format.

5) The program outputs the received accommodation information (see Table II) into search result sheet.

6) Based on latitudes and longitudes of the accommodations, the program generates a HTML page requesting map information and uploads it to user's web server.

7) User's web server sends a URL request based on the HTML page of (6) to Google Map server.

8) Google Map server returns map information which contains map markers of the accommodations to user's web server.

9) The program receives the HTML page containing Google Map and accommodation markers and then displays it on the web browser form of the program.

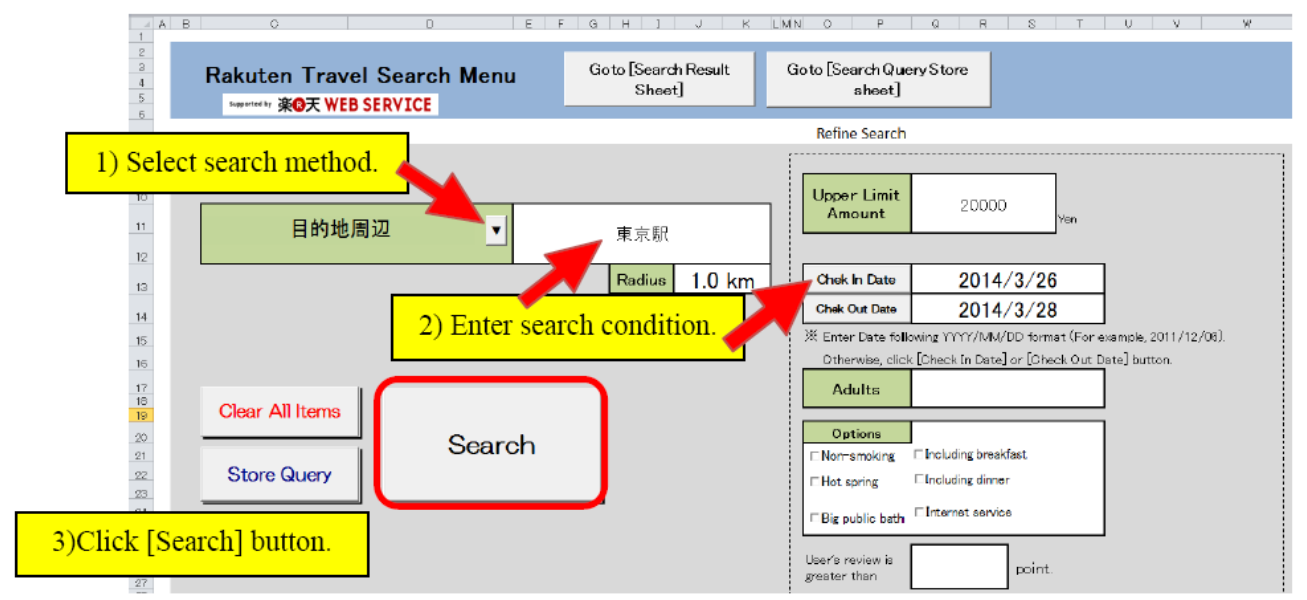

Fig. 3. An example of a screen shot showing menu sheet.

\section{Search Procedure}

Users can conduct a search by entering search condition at Menu sheet or re-entering search condition at [Search Result sheet]. This section introduces search procedure at Menu sheet.

1) Pressing $\nabla$ button to display the list of search methods and select one of the following search methods: accommodation search by keywords, accommodation 
search by prefecture, accommodation search by the place of destination.

2) Enter refined search options (such as, check-in date, check-out date, etc.), and then press the search button. Fig. 3 depicts a screen shot of [Menu Sheet] showing the search condition that finds accommodations which are not far from Tokyo station more than 1 kilometer and upper limit room charge/day is not greater than 20,000 yen.

3) Click [Search button].

4) The program automatically outputs the search result into [Search Result Sheet]. Fig. 4 depicts a screen shot showing the result of the search condition shown in Fig. 3. This sheet has a table storing a list of accommodations that meet the search condition. Each row of the table stores the following information.

- the sequence number,

- accommodation name embedded with URL link of the homepage presenting the detail of the accommodation,

- the lowest room charge, and

- the average value of customers' review where the maximum value is five.

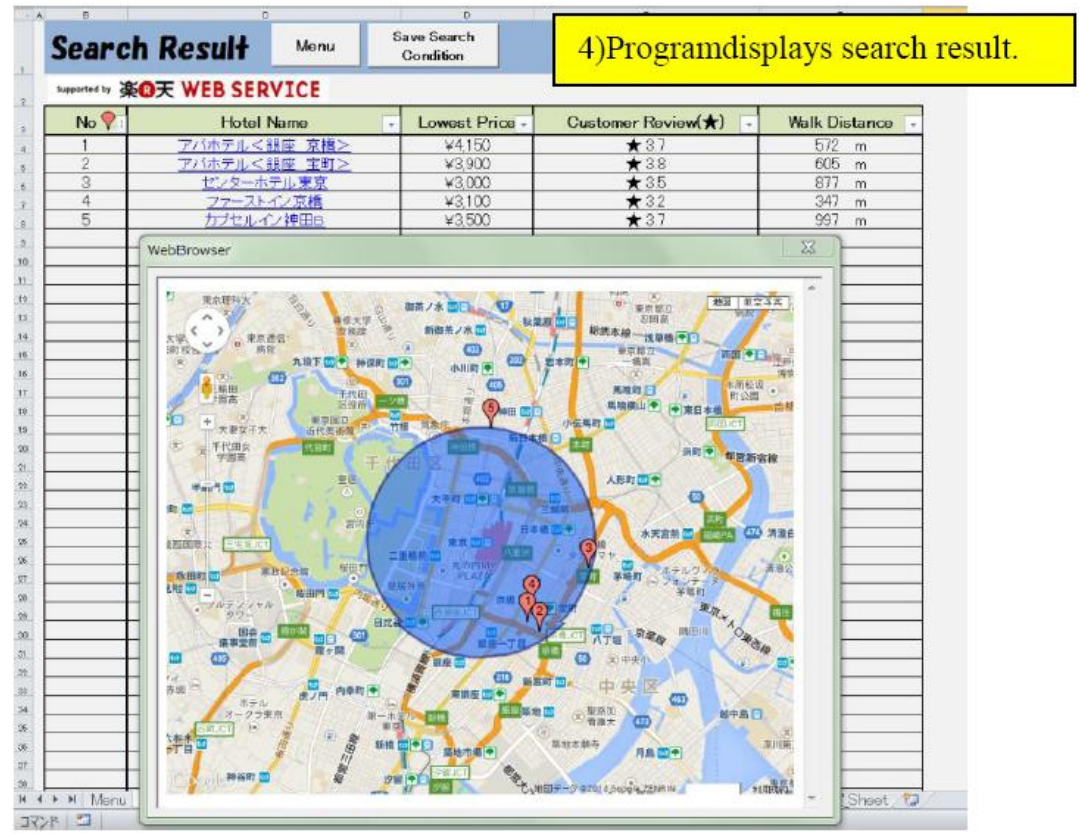

Fig. 4. An example of a screen shot showing [search result sheet].

TABLE II: THE ACCOMMODATION INFORMATION RECEIVED FROM RAKUTEN TRAVEL'S SERVERS AND GOOGLE MAP'S SERVERS

\begin{tabular}{|l|l|}
\hline \multicolumn{1}{|c|}{ Information of Server of Rakuten Travel } & \multicolumn{1}{|c|}{ Information of Server of Google Map } \\
\hline Accommodation Number (hotelNo) & Name of the place of destination (long_name) \\
\hline Accommodation Name (hotelName) & Latitude of the place of destination (lat) \\
\hline $\begin{array}{l}\text { Average value of user's review on the } \\
\text { accommodation (reviewAverage) }\end{array}$ & \multirow{2}{*}{ Longitude of the place of destination (lng) } \\
\hline Minimum room charge (hotelMinCharge) & \\
\hline Latitude of the accommodation (latitude) & \\
\hline Longitude of the accommodation (longitude) & \\
\cline { 1 - 1 } $\begin{array}{l}\text { URL address of web page describing detail } \\
\text { accommodation plan (planListUrl) }\end{array}$ & \\
\hline
\end{tabular}

TABLE III: COMPARISON OF SEARCH FUNCTIONS OF THIS SYSTEM WITH THOSE OF OTHER ACCOMMODATION BOOKING Web Site

\begin{tabular}{|l|c|c|c|c|}
\hline & Proposed System & Chizuyado [13] & Hotel-Kensaku [14] & Raku360 [15] \\
\hline $\begin{array}{l}\text { (1) Accommodation search by the } \\
\text { place of destination }\end{array}$ & 0 & $\circ$ & $\times$ & $\circ$ \\
\hline $\begin{array}{l}\text { (2) Accommodation search by } \\
\text { prefectures }\end{array}$ & 0 & $\times$ & $\times$ & $\times$ \\
\hline (3) Refinc Scarch option & 0 & $\times$ & $\circ$ & 0 \\
\hline (4) Combination of (1), (2) and (3) & 0 & $\times$ & $\times$ & 0 \\
\hline $\begin{array}{l}\text { (5) Display accommodation on the } \\
\text { map }\end{array}$ & 0 & $\circ$ & $\circ$ & $\circ$ \\
\hline $\begin{array}{l}\text { (6) Calculation of distance from } \\
\text { accommodation to the place of } \\
\text { destination }\end{array}$ & 0 & $\times$ & $\times$ & $\times$ \\
\hline
\end{tabular}

As the result of accommodation search by the place of destination, the program displays Google Map window showing the locations of the accommodations on the map. Consider Google Map windows on the right of the screen shot of Fig. 4. The light blue circle denotes the area whose center point is Tokyo Station which is the place of destination. The circle radius is equal to 1 kilometer which is the maximum distance from Tokyo Station. Map markers denote the locations of the accommodations. A number on each map marker indicates the sequence number of corresponding accommodation in the table. When the user moves the mouse cursor over a marker, the Google Map window automatically displays the corresponding accommodation name. Users can open a web browser displaying the accommodation detail by clicking the name of the accommodations of the table which they want to display. Since the search result is stored in as table data (see Fig. 4), users can use filter and sort functions of Excel to re-arrange the result in proper format. Comparison of search functions of this system and other accommodation booking sites is shown in Table III.

\section{CONCLUSION}

We have presented a methodology that employs Excel as a toolwhich integratesweb services' data and processesthe data offline. Based on this methodology, developers use VBA of Excel to develop the web applications which have not yet provided by web sites. Excel can be connected to external data such as a web page, a database, an XML file, a text file, or in one of many other places. Based on Excel's external 
data source connectivity and web service APIs, developers can develop a program that requests web services of web sites simultaneously and process the output data of requested web service offline. By using built-in or intrinsic functions of Excel, developers can create calculations and data transformation routines in an Excel worksheet in a fraction of the time that it takes to do the same in code of other software language. Based on the presented methodology, we have developed an Excel-based online accommodation search program that integrates web services of Google map and Rakuten Travel which is the biggest accommodation booking web site of Japan. The outstanding features this program are three new accommodation search functions (accommodation search by the place of destination, accommodation search by prefectures, and accommodation search by keyword) for Rakuten Travel. Since the search result is stored in as table data of an Excel sheet, users can use filter and sort functions of Excel to re-arrange the search result in proper format.

\section{REFERENCES}

[1] I. Ermilov, S. Auer, and C. Stadler, "User-driven semantic mapping of tabular data," in Proc. the 9th International Conference on Semantic Systems, pp. 85-91, 2013.

[2] D. Draheim, P. Thiemann, and G. Webster, "A spreadsheet client for web applications," in Proc. the 6th international conference on Next Generation Information Technologies and Systems, pp. 274-286, 2006.

[3] D. Lkhamsuren and Y. Tanaka, "PadSpace: A new framework for the service federation of web resources," Information Systems Frontiers, vol. 15, issue 1, pp. 111-132, March 2013.

[4] Microsoft Excel. (2010). [Online]. Available: http://office.microsoft.com/en-us/excel/excel-2010-features-and-benef its-HA101806958.aspx

[5] R. Shepherd, Excel 2007 VBA Macro Programming, 2nd edition, McGraw-Hill Inc., 2009.
[6] W3C. Extensible Markup Language (XML) 1.0 (Fourth Edition). (2006). [Online]. Available: http://www.w3. org/TR/2006/REC-xml-20060816/

[7] J. Korol, Excel 2003 VBA programming with XML and ASP, Wordware Publishing, 2006.

[8] M. Chen, "Factors affecting the adoption and diffusion of XML and Web services standards for e-business systems," International Journal of Human Computer Studies vol 58, no. 3, pp. 259-279, 2003.

[9] F. Yang, N. Gupta, N. Gerner, X. Qi, A. Demers, J. Gehrke, and J. Shanmugasundaram, "A unified platform for data driven web applications with automatic client-server partitioning," in Proc. the 16th international conference on World Wide Web, pp. 341-350, 2007.

[10] C. Eric and L. Eric, Visual Studio Tools for Office Using Visual Basic 2005 with Excel, Word, Outlook, and InfoPath, Addison-Wesley, 2006.

[11] Rakuten. (2013). Rakuten Travel APIs (Version: 2013-10-24). [Online]. Available: http://webservice.rakuten.co.jp/api/simplehotelsearch/

[12] Google. (2014). Google Maps JavaScript API v3. [Online]. Available: https://developers.google.com/maps/documentation/javascript/basics

[13] Chizuyado. (2014). [Online]. Available: http://www.chizuyado.com/

[14] Hotel-Kensaku. (2014). [Online]. Available: http://hotel.jp/\#hg-areamap-bx

[15] Raku360. (2014). [Online]. Available: http://travel.raku360.com/

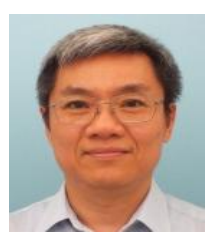

Somchai Chatvichienchai received the BS, MS degrees in computer engineering from Chulalongkorn University in 1977, Kyushu University in 1989, respectively, and the PhD degree in informatics from Kyoto University in 2004. Somchai joined the Department of Info-Media at Siebold University of Nagasaki in 2004 and was a full-time professor of Dept. of Information and Media Studies in 2009. Dr. Somchai's research interests include database theory and systems, XML, Access Control, and information retrieval. Dr. Somchai is a member of the ACM, IEEE, IAENG, and the Database Society of Japan (DBSJ).

Wataru Miyagi was a student of Dept. of Information and Media Studies of university of Nagasaki. His research interests include XML and Web information retrieval. He graduated from university of Nagasaki in March 2014. 